\title{
Anti-diabetic effect of sorghum extract on hepatic gluconeogenesis of streptozotocin-induced diabetic rats
}

\author{
Jungmin Kim and Yongsoon Park
}

\begin{abstract}
Background: It has been suggested that Sorghum, a rich source of phytochemicals, has a hypoglycemic effect, but the mechanism is unknown. We investigated the effects of oral administration of sorghum extract (SE) on hepatic gluconeogenesis and the glucose uptake of muscle in streptozotocin-induced diabetic rats for six weeks.

Methods: Male Wistar rats were divided in five groups ( $n=5$ per group): normal control (NC), rats with STZ-induced diabetic mellitus (DM), diabetic rats administrated $0.4 \mathrm{~g} / \mathrm{kg}$ body weight of SE (DM-SE 0.4) and $0.6 \mathrm{~g} / \mathrm{kg}$ body weight of SE (DM-SE 0.6), and diabetic rats administrated $0.7 \mathrm{mg} / \mathrm{kg}$ body weight of glibenclamide (DM-G).

Results: Administration of SE and G reduced the concentration of triglycerides, total and LDL-cholesterol and glucose, and the area under the curve of glucose during intraperitoneal glucose tolerance tests down to the levels observed in non-diabetic rats. In addition, administration of 0.4 and $0.6 \mathrm{~g} / \mathrm{kg} \mathrm{SE}$ and $0.7 \mathrm{mg} / \mathrm{kg}$ glibenclamide (G) significantly reduced the expression of phosphoenolpyruvate carboxykinase and the phosphor-p38/p38 ratio, while increased phosphor adenosine monophosphate activated protein kinase (AMPK)/AMPK ratio, but the glucose transporter 4 translocation and the phosphor-Akt/Akt ratio was significantly increased only by administration of $\mathrm{G}$.

Conclusions: These results indicate that the hypoglycemic effect of SE was related to hepatic gluconeogenesis but not the glucose uptake of skeletal muscle, and the effect was similar to that of anti-diabetic medication.
\end{abstract}

Keywords: Diabetic rats, Hepatic gluconeogenetic enzyme expression, Sorghum

\section{Background}

Diabetes mellitus is a metabolic disease characterized by chronic hyperglycemia [1] caused by increased hepatic glucose production [2] or abnormal glucose use in skeletal muscle [3]. Phosphoenolpyruvate carboxykinase (PEPCK), an important enzyme of gluconeogenesis, is regulated by the adenosine monophosphate activated protein kinase (AMPK) or p38 pathways [4,5]. Additionally, glucose transporter (GLUT4) is a rate-limiting factor for glucose uptake in skeletal muscle, and Akt (protein kinase B) is a central mediator of insulininduced GLUT4 translocation from cytosol to membrane [6]. These protein expressions have been shown to be associated with the pathogenesis in streptozotocin (STZ)-induced diabetic rats [7-9].

\footnotetext{
* Correspondence: yongsoon@hanyang.ac.kr

Department of Food and Nutrition, Hanyang University, 222 Wangsimni-ro, Seoul, Seongdong-gu 133-791, Korea
}

Because of the adverse effects of diabetic medication such as the pain by injection, insulin resistance or hypoglycemic symptoms, there is increasing investigation into the use of herbs and plants for the treatment of diabetic mellitus. Sorghum bicolor L. Monech is the fifth most important cereal crop worldwide, both in terms of planted area and metric tons harvested [10]. Sorghum flour is a rich source of phytochemicals, tannins, phenolic acids, anthocyanins, phytosterols, and policosanols, and these bioactive components have been reported to have antioxidant $[11,12]$, anti-carcinogenic [13], and cholesterol-lowering properties [14,15]. Previously, sorghum extracts have been shown to have hypoglycemic activity in STZ-induced diabetic rats [16]; however, the mechanism is unclear. Thus, we investigated the hypothesis that sorghum extract (SE) has hypoglycemic effects through inhibition of hepatic 
gluconeogenic enzymes and/or the increase in glucose uptake in skeletal muscle in STZ-induced diabetic rats.

\section{Methods}

Animals and diet

Protocol approved by the Institutional Animal Care and Use Committee of Hanyang University was used for all animal experiments (HY-IACUC-11-059). Six week old male Wistar rats (Orient, Gyeonggi-do, Korea) were housed in individual ventilated in an air-conditioned room maintained at $22 \pm 2^{\circ} \mathrm{C}$ with a $12 \mathrm{~h}$ light-dark cycle. After one week of acclimatization, twenty rats were intraperitonially injected with $\mathrm{STZ}(70 \mathrm{mg} / \mathrm{kg}$ body weight in $0.05 \mathrm{M}$ citrate buffer; Sigma Co, St. Louis, MO, USA) once, and then blood glucose concentration was measured to confirm the development of diabetes mellitus. After 3 days of STZ injection, twenty STZinduced diabetic rats and five normal rats without STX injection were fed with an AIN-93M diet (Research Diets, New Brunswick, NJ, USA) and water ad libitum for 6 weeks, and the body weight and food intake were recorded every week.

Sorghum (Sorghum bicolor L. Moench cv. Hwanggeumchal-susu) was grown at the Department of Functional Crops, National Institute of Crop Science, Rural Development Administration, Milyang, Korea during the 2010 growing season. Voucher herbarium specimens were deposited with the reference number (KNICS-579) in the Herbarium of the Department of Functional Crops. The botanical identification was made by Dr. IllMin Chung of Konkuk University [16]. Sorghum was finely ground using a Pin-type Mill (DK-201, Sejung Tech, Daegu, Korea) and extracted using $80 \%$ fermented ethanol at room temperature for $24 \mathrm{~h}$ while shaking (WiseCube WIS-RL010, Daihan Scientific Co., Ltd., Seoul, Korea). The extracts were centrifuged at 5,000 g for $30 \mathrm{~min}$ and the supernatants were filtered through Advantec 2 filter paper (Advantec Toyo Kaisha Ltd., Tokyo, Japan). The filtrates were evaporated using a rotary evaporator (Eyela N-1000, Tokyo Rikakikai Co., Tokyo, Japan) at $40^{\circ} \mathrm{C}$, and then freeze-dried in vacuum (FDT-8612, OPERON, Kimpo, Korea). The dried extract was stored at $-20^{\circ} \mathrm{C}$.

During a six-week period of diet, normal control rats (NC) were orally administrated $0.1 \mathrm{~mL}$ of saline, and twenty STZ-induced diabetic rats were randomly divided into four groups that orally administrated either $0.1 \mathrm{~mL}$ of saline (DM) or $0.1 \mathrm{~mL}$ of saline with a $0.4 \mathrm{~g} / \mathrm{kg}$ body weight of SE (DM-SE 0.4), $0.6 \mathrm{~g} / \mathrm{kg}$ body weight of SE (DM-SE 0.6 ) or $0.7 \mathrm{mg} / \mathrm{kg}$ body weight of glibenclamide (DM-G) using gavage ( $\mathrm{n}=5$ per group).

Intraperitoneal glucose tolerance tests (IPGTT) were performed by intraperitoneal injection of $25 \%$ glucose ( 2 $\mathrm{g} / \mathrm{kg}$ body weight) on the last day of the experiment after an overnight fast. Blood samples were collected from the tail vein at 30, 60, and $120 \mathrm{~min}$ after injection.

At the end of the experimental period, all rats were anesthetized with an intraperitoneal injection of tiletamine $(25 \mathrm{mg} / \mathrm{kg})$, zolazepam $(25 \mathrm{mg} / \mathrm{kg})$, and xylazine $(10 \mathrm{mg} / \mathrm{kg})$ after overnight fasting. Blood was collected into SST tubes (BD Vacutainer, Franklin Lakes, NJ, USA) and centrifuged at $3000 \mathrm{~g}$ for $15 \mathrm{~min}$ (HA 1000-3, Hanil Sciences Industrial CO. Ltd., Incheon, Korea). Organs and adipose tissues were harvested, rinsed with saline and then weighed [17]. Serum and tissue samples were stored at $-80^{\circ} \mathrm{C}$.

\section{Biochemical assays}

Glucose concentration during IPGTT was determined with AccuCheck (Roche Diagnostics, Indianapolis, IN, USA). The values of the area under the glucose time curve (AUC) were calculated using the glucose levels at each time point during IPGTT. The serum levels of triglycerides, total- and HDL-cholesterol, glucose, glutamic oxaloacetic transaminase (GOT), and glutamic pyruvic transaminase (GPT) were determined using a commercially available kit (Asan Pharm., Hwaseong, Korea) with a spectrophotometer (DU 600, Beckman Coulter, Inc., Indianapolis, IN, USA). LDL-cholesterol concentration was calculated using the Friedwald formula. The serum insulin level was determined using an ultra-sensitive rat insulin enzyme linked immunosorbent assay kit (Crystal Chem, Downers Grove, IL, USA) with a microplate reader (iMark, Bio-Rad Laboratories, Hercules, CA, USA).

\section{Western blotting}

Liver and skeletal muscles were homogenized in a $0.8 \mathrm{ml}$ ice-cold lysis buffer (20 mM HEPES, $0.25 \mathrm{M}$ sucrose, $0.5 \mathrm{mM}$ EDTA, $2 \mathrm{mM}$ dithiothreitol, $1 \mathrm{mM}$ PMSF, $10 \mu \mathrm{g} / \mathrm{mL}$ leupeptin, $10 \mu \mathrm{g} / \mathrm{mL}$ aprotinin, and $1 \mathrm{mM}$ $\mathrm{Na}_{3} \mathrm{VO}_{4}, \mathrm{pH}$ 7.5). The homogenates were centrifuged at $10,000 \mathrm{~g}$ for $15 \mathrm{~min}$ at $4^{\circ} \mathrm{C}$, and the supernatant was centrifuged at $20,000 \mathrm{~g}$ for $1 \mathrm{~h}$ at $4^{\circ} \mathrm{C}$ to obtain cytosolic fraction. For the membrane fraction of skeletal muscle, the pellets were re-suspended in $250 \mu \mathrm{l}$ of lysis buffer and $1 \%(\mathrm{v} / \mathrm{v})$ triton $\mathrm{X}-100$, incubated on ice for $30 \mathrm{~min}$, and centrifuged at $200,000 \mathrm{~g}$ for $30 \mathrm{~min}$ at $4^{\circ} \mathrm{C}$. The protein concentrations were determined using a Bradford assay with bovine serum albumin (Bio-Rad, Hercules, CA, USA) as the standard. Equal amounts of protein $(30 \mu \mathrm{g})$ from liver or skeletal muscle was separated on $8 \%$ SDS-PAGE and transferred to a polyvinylidine fluoride membrane $(0.45 \mu \mathrm{m}$, Immobilon-P transfer membrane, Millipore, USA). After blocking, the membranes were incubated overnight with a primary antibody for PEPCK (1:1,000, Cell Signaling Technology, Beverly, MA, USA), p38 (1:1,000, Cell Signaling Technology, Beverly, MA, 
USA), phospho p-38 (1:500, Cell Signaling Technology, Beverly, MA, USA), AMPK (1:1,000, Cell Signaling Technology, Beverly, MA, USA), phospho AMPK (1:500, Cell Signaling Technology, Beverly, MA, USA), GLUT4 (1:2000, abCam, Cambridge, UK), Akt (1:1,000, Cell Signaling Technology, Beverly, MA, USA), or phospho-Akt (1:500, Cell Signaling Technology, Beverly, MA, USA) in Tris-buffered saline with Tween 20 (TBST) containing $5 \%$ nonfat milk at $4^{\circ} \mathrm{C}$. After washing in TBST, the membranes were incubated with horseradish peroxidase conjugated goat anti-rabbit or mouse IgG (1:5,000, Cell Signaling Technology, Beverly, MA, USA) for $1 \mathrm{~h}$. The immunoreactive signals were developed using an enhanced chemiluminescence kit (GE Healthcare Life Sciences, Piscataway, NJ, USA) and exposed to Kodak film. The relative and normalized protein expression was calculated by $\beta$-action (1:1,000, BD Transduction Laboratories, NJ, USA).

\section{Statistical analysis}

All data are expressed as the mean \pm standard error of the mean (SEM). Statistical differences among the groups were calculated by the analysis of variance (ANOVA) followed by Duncan's multiple range test (SPSS 18.0 version., Chicago, IL, USA). Differences with $\mathrm{p}<0.05$ were considered significant.

\section{Results}

\section{Food intake, body weight, and organ weights}

Dietary intake, and weight of liver and kidney as percentage of body weight were significantly greater in all DM groups than in the NC group, but body weight and weight of retroperitoneal, epididymal and perirenal adipose tissues were significantly lower in all DM groups than in the NC group (Table 1). Among the DM groups, there were no significant differences in dietary intake, body weight and weight of adipose tissue, liver and kidney.
Levels of glucose, insulin lipid profiles, and liver function Serum concentrations of triglycerides, and total- and LDL-cholesterol were significantly lower in the DM-SE 0.4 , DM-SE 0.6, DM-G, and NC groups than the DM group, while HDL-cholesterol level was significantly lower in DM-G than the other DM and NC groups (Table 2). There were no significant differences in serum levels of glutamic oxaloacetic transaminase and glutamic pyruvic transaminase, suggesting that SE had no harmful effect on liver function. Serum glucose concentration and AUC during IPGTT were significantly lower in DMSE 0.6 and DM-G than in DM, but not DM-SE 0.4 (Table 2). Serum insulin level in DM-G was significantly increased up to that of NC, but SE had no significant effect on insulin concentration. Blood glucose levels reached a peak at 30 min during IPGTT (Figure 1), and the peak concentrations of glucose were significantly lower in DM-SE 0.4 and DM-SE 0.6 than DM, but higher than NC and DM-G (Figure 1).

\section{Protein expression in liver and muscle}

The expression of PEPCK and the phosphor-p38/p38 ratio were significantly lower, while the phospho-AMPK/ AMPK ratio was significantly higher in NC, DM-SE 0.4, DM-SE 0.6, and DM-G than in DM, suggesting that SE and $\mathrm{G}$ decreased hepatic gluconeogenesis (Figure 2). Phosphorylation of Akt and GLUT4 translocation was significantly decreased in DM as compared with NC, but SE had no significant effect (Figure 3). On the other hand, GLUT4 translocation was significantly increased by the administration of $G$, suggesting that $G$ reduced blood glucose levels by both reducing hepatic gluconeogenesis and increasing glucose uptake by muscle.

\section{Discussion}

The present study demonstrates that oral administration of SE significantly reduces blood glucose concentration

Table 1 Dietary intake, body weight and various organ weights

\begin{tabular}{|c|c|c|c|c|c|}
\hline & NC & DM & DM-SE 0.4 & DM-SE 0.6 & DM-G \\
\hline Dietary intake (g/day) & $22.10 \pm 0.23^{a}$ & $25.94 \pm 1.30^{b}$ & $26.65 \pm 1.60^{b}$ & $28.41 \pm 1.26^{b}$ & $27.11 \pm 1.27^{b}$ \\
\hline Initial body weight (g/day) & $246.20 \pm 6.76^{a}$ & $208.60 \pm 7.79^{b}$ & $213.20 \pm 7.36^{b}$ & $206.60 \pm 9.27^{b}$ & $207.80 \pm 14.15^{b}$ \\
\hline Final body weight (g/day) & $491.40 \pm 9.01^{\mathrm{a}}$ & $375.40 \pm 43.17^{b}$ & $347.60 \pm 35.94^{b}$ & $385.40 \pm 30.44^{b}$ & $323.40 \pm 38.45^{b}$ \\
\hline Liver (mg/g body weight) & $11.52 \pm 0.57^{\mathrm{a}}$ & $11.40 \pm 0.66^{b}$ & $12.27 \pm 0.63^{b}$ & $12.04 \pm 0.30^{b}$ & $10.83 \pm 0.69^{b}$ \\
\hline kidney (mg/g body weight) & $2.73 \pm 0.10^{a}$ & $2.91 \pm 0.07^{b}$ & $2.65 \pm 0.08^{b}$ & $2.72 \pm 0.06^{b}$ & $2.83 \pm 0.11^{b}$ \\
\hline Retroperitoneal fat (g) & $12.11 \pm 1.07^{\mathrm{a}}$ & $8.52 \pm 0.62^{b}$ & $8.32 \pm 1.60^{b}$ & $8.99 \pm 0.56^{b}$ & $6.78 \pm 0.34^{b}$ \\
\hline Epididymal fat (g) & $11.82 \pm 0.81^{\mathrm{a}}$ & $8.97 \pm 0.27^{b}$ & $6.73 \pm 1.44^{b}$ & $8.68 \pm 0.35^{b}$ & $6.40 \pm 1.27^{b}$ \\
\hline Perirenal fat (g) & $0.99 \pm 0.21$ & $0.93 \pm 0.15$ & $0.94 \pm 0.15$ & $0.75 \pm 0.15$ & $0.84 \pm 016$ \\
\hline
\end{tabular}

Values are expressed as the mean \pm SEM $(n=5)$; NC, normal control rats administrated saline; DM, rats with diabetes mellitus administrated saline; DM-SE 0.4, rats with diabetes mellitus administrated $0.4 \mathrm{~g} / \mathrm{kg}$ body weight of sorghum extract; DM-SE 0.6 , rats with diabetes mellitus administrated $0.6 \mathrm{~g} / \mathrm{kg}$ body weight of sorghum extract; DM-G, rats with diabetes mellitus administrated $0.7 \mathrm{mg} / \mathrm{kg}$ body weight of glibenclamide. The values in the rows with different letters are significantly different at $p<0.05$ using ANOVA with Duncan's multiple range test. 
Table 2 Lipid profiles, liver function, and levels of glucose and insulin in serum

\begin{tabular}{lccccc}
\hline & NC & DM & DM-SE 0.4 & DM-SE 0.6 & DM-G \\
\hline Triglycerides (mmol/L) & $0.92 \pm 0.15^{\mathrm{a}}$ & $1.86 \pm 0.13^{\mathrm{b}}$ & $0.75 \pm 0.13^{\mathrm{a}}$ & $0.68 \pm 0.12^{\mathrm{a}}$ & $0.89 \pm 0.02^{\mathrm{a}}$ \\
Total cholesterol (mmol/L) & $2.01 \pm 0.10^{\mathrm{a}}$ & $2.70 \pm 0.19^{\mathrm{b}}$ & $1.81 \pm 0.05^{\mathrm{a}}$ & $1.81 \pm 0.06^{\mathrm{a}}$ & $2.14 \pm 0.10^{\mathrm{a}}$ \\
HDL-cholesterol (mmol/L) & $1.20 \pm 0.04^{\mathrm{a}}$ & $1.33 \pm 0.02^{\mathrm{a}}$ & $1.28 \pm 0.02^{\mathrm{a}}$ & $1.34 \pm 0.06^{\mathrm{a}}$ & $1.02 \pm 0.09^{\mathrm{b}}$ \\
LDL-cholesterol (mmol/L) & $0.73 \pm 0.03^{\mathrm{a}}$ & $1.25 \pm 0.07^{\mathrm{b}}$ & $0.82 \pm 0.07^{\mathrm{a}}$ & $0.72 \pm 0.04^{\mathrm{a}}$ & $0.88 \pm 0.05^{\mathrm{a}}$ \\
Glutamic oxaloacetic transaminase (IU/L) & $42.81 \pm 1.19$ & $46.02 \pm 2.92$ & $42.94 \pm 2.05$ & $44.26 \pm 0.73$ & $45.03 \pm 1.52$ \\
Glutamic pyruvic transaminase (IU/L) & $14.54 \pm 3.45$ & $12.72 \pm 1.20$ & $13.78 \pm 1.94$ & $10.17 \pm 0.73$ & $9.68 \pm 1.96$ \\
Glucose (mmol/L) & $1.18 \pm 0.06^{\mathrm{a}}$ & $1.67 \pm 0.12^{\mathrm{c}}$ & $1.51 \pm 0.07^{\mathrm{bc}}$ & $1.29 \pm 0.02^{\mathrm{b}}$ & $1.21 \pm 0.12^{\mathrm{a}}$ \\
Insulin (pmol/L) & $3.73 \pm 0.27^{\mathrm{a}}$ & $1.25 \pm 0.20^{\mathrm{b}}$ & $1.64 \pm 0.26^{\mathrm{ab}}$ & $1.91 \pm 0.11^{\mathrm{ab}}$ & $3.69 \pm 1.46^{\mathrm{a}}$ \\
AUC of glucose (mmol.min/L) & $748.25 \pm 27.39^{\mathrm{a}}$ & $1250.25 \pm 35.24^{\mathrm{c}}$ & $881.20 \pm 39.61^{\mathrm{b}}$ & $907.76 \pm 29.55^{\mathrm{b}}$ & $781.39 \pm 23.36^{\mathrm{a}}$ \\
\hline
\end{tabular}

Values are expressed as mean \pm SEM $(n=5)$; NC, normal control rats administrated saline; DM, rats with diabetes mellitus administrated saline; DM-SE 0.4, rats with diabetes mellitus administrated $0.4 \mathrm{~g} / \mathrm{kg}$ body weight of sorghum extract; DM-SE 0.6 , rats with diabetes mellitus administrated $0.6 \mathrm{~g} / \mathrm{kg}$ body weight of sorghum extract; DM-G, rats with diabetes mellitus administrated $0.7 \mathrm{mg} / \mathrm{kg}$ body weight of glibenclamide; AUC, area under the curve during intraperitoneal glucose tolerance tests. The values in the rows with different letters were significantly different at $p<0.05$ using ANOVA with Duncan's multiple range test.

in STZ-induced diabetic rats by inhibiting hepatic gluconeogenesis through suppression of PEPCK and p38 expression and increases AMPK expression. However, SE had no significant effect on glucose uptake by skeletal muscle determined by GLUT4 translocation and Akt phosphorylation, suggesting that the hypoglycemic effects of SE may be related to an insulin independent pathway.

These hypoglycemic effects were consistent with the results of a recent study that found that SE rich tannins at dosages of $0.25-0.5 \mathrm{~g} / \mathrm{kg}$ of body weight significantly decreased serum glucose concentration in STZ-induced diabetic rats [16] and mice fed a high fat diet [18]. A previous study showed that SE strongly inhibited in vitro activities of $\alpha$-glucosidase and $\alpha$-amylase, targets for the development of diabetic drugs [19]. Lakshmi et al. [20] also reported that sorghum grain significantly reduced the fasting glucose level and the AUC of glucose in type 2 diabetic patients. The SE used in the present study was $0.4-0.6 \mathrm{~g} / \mathrm{kg}$ of body weight, which was translated as 20-30 g of sorghum grain per $\mathrm{kg}$ of body weight for human. Due to the low yield rate, it may not be achievable to reduce blood glucose levels by consumption of intact sorghum grain.

In the present study, administration of SE significantly reduced the expression of PEPCK and phosphor-p38, while increasing phosphor-AMPK. Expression of PEPCK is an important factor responsible for hepatic gluconeogenesis [2,21], and has previously been shown to increase in the liver of diabetic rats $[7,8]$. In addition, the p38 pathway increased the expression of PEPCK $[8,22,23]$, but the p38-activated PEPCK signal pathway

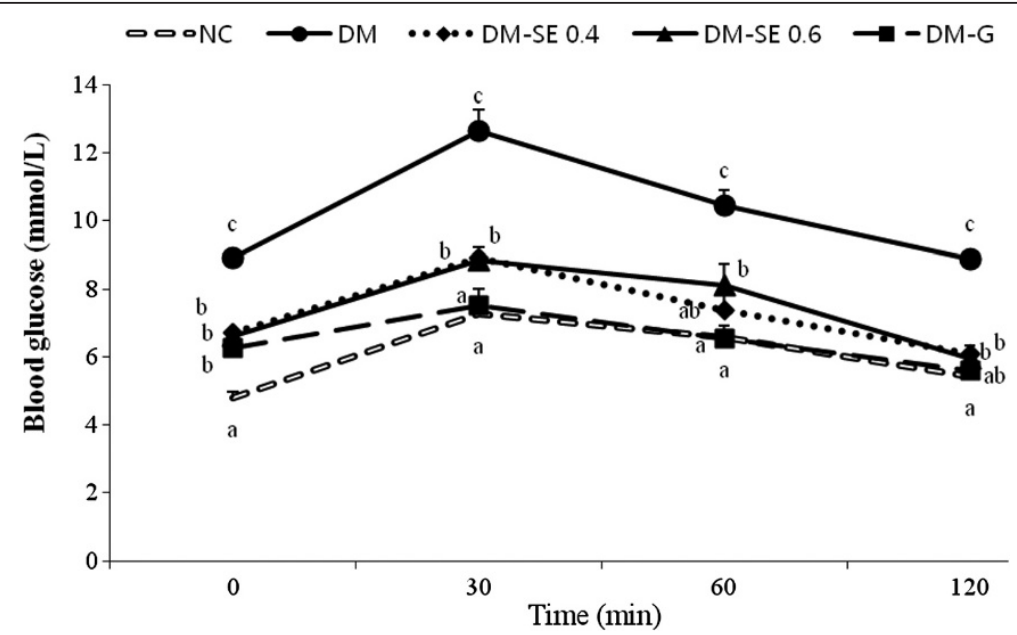

Figure 1 Blood glucose levels during the intraperitoneal glucose tolerance tests. NC, normal control rats administrated saline; DM, rats with diabetes mellitus administrated saline; DM-SE 0.4, rats with diabetes mellitus administrated $0.4 \mathrm{~g} / \mathrm{kg}$ body weight of sorghum extract; DM-SE 0.6, rats with diabetes mellitus administrated $0.6 \mathrm{~g} / \mathrm{kg}$ body weight of sorghum extract; DM-G, rats with diabetes mellitus administrated $0.7 \mathrm{mg} / \mathrm{kg}$ body weight of glibenclamide. The values are mean \pm SEM $(n=5)$. Values with different superscripts are significantly different at $p<0.05$ using ANOVA with Duncan's multiple range test. 


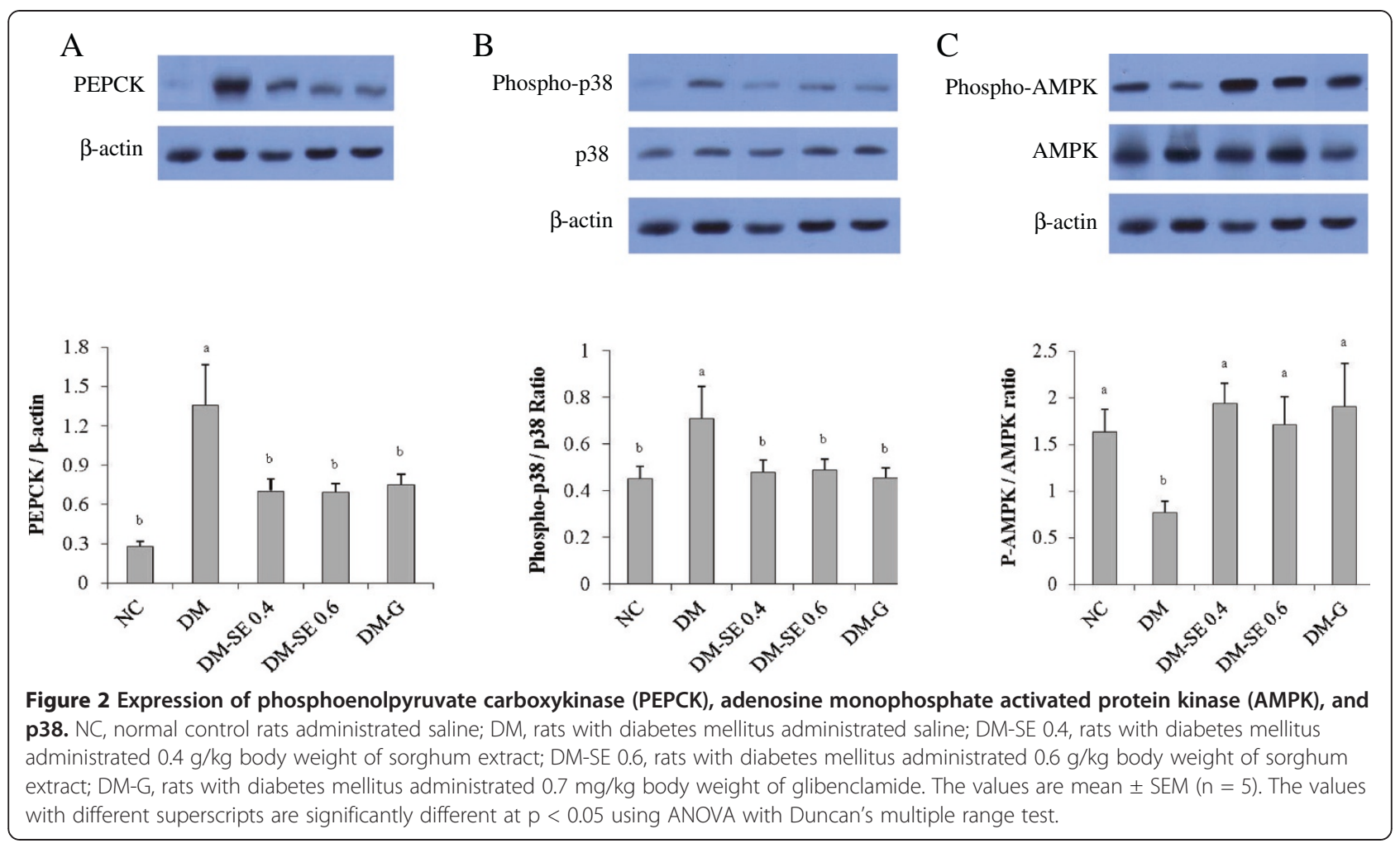

\section{A}
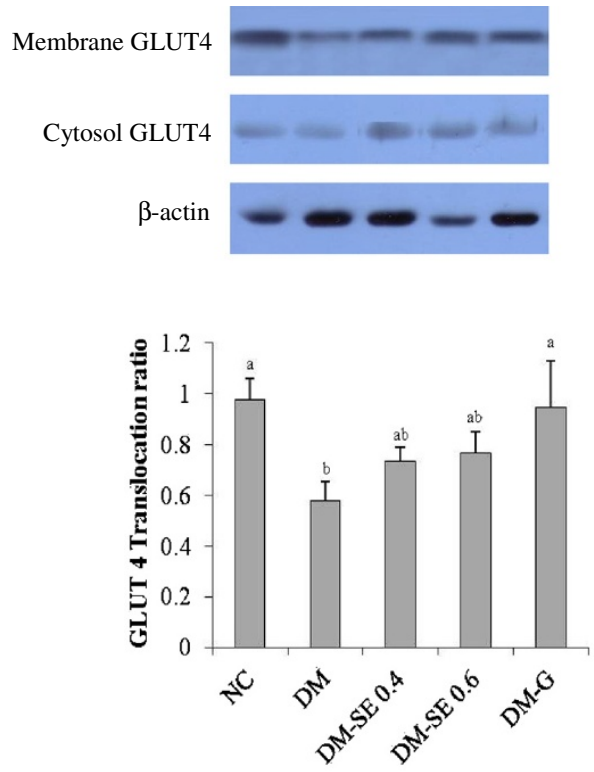

B
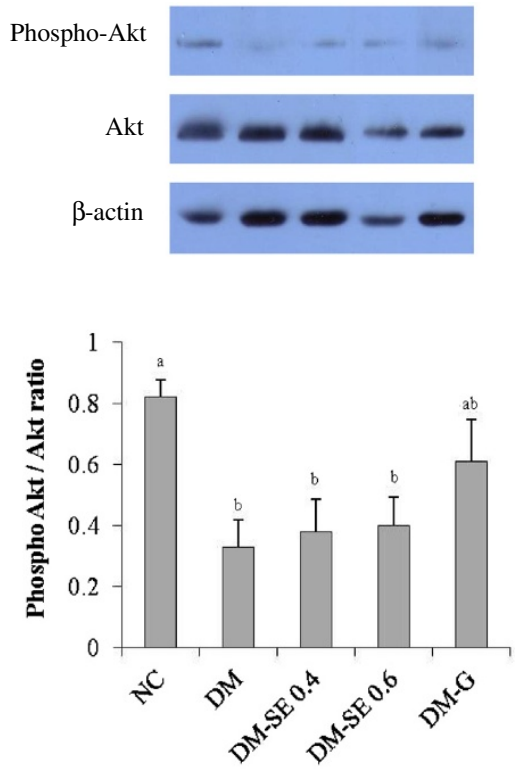

Figure 3 Expression of the glucose transporter (GLUT) 4 and Akt (protein kinase B). NC, normal control rats administrated saline; DM, rats with diabetes mellitus administrated saline; DM-SE 0.4 , rats with diabetes mellitus administrated $0.4 \mathrm{~g} / \mathrm{kg}$ body weight of sorghum extract; DM-SE 0.6 , rats with diabetes mellitus administrated $0.6 \mathrm{~g} / \mathrm{kg}$ body weight of sorghum extract; DM-G, rats with diabetes mellitus administrated $0.7 \mathrm{mg} / \mathrm{kg}$ body weight of glibenclamide. The values are mean \pm SEM $(n=5)$. The values with different superscripts are significantly different at $p<0.05$ using ANOVA with Duncan's multiple range test. 
has been shown to be inhibited by AMPK $[8,24]$. It has also been reported that the AMPK- $\alpha 2$ catalytic subunit is a key target for the regulation of hepatic glucose production by adiponectin and leptin but not insulin, suggesting that AMPK is regulated by a mechanism distinct from insulin $[7,25,26]$. Since we observed that SE significantly reduced blood glucose concentration but did not significantly change insulin levels, these results indicate that $\mathrm{SE}$ reduces hepatic gluconeogenesis through an insulin independent pathway.

GLUT4 is the rate-limiting step for glucose uptake by an insulin dependent pathway in skeletal muscle [27], and GLUT4 translocation from cytosol to the plasma membrane is regulated by Akt $[9,28]$. Previous studies have observed that blood glucose levels increase with reductions of insulin concentration in GLUT4 knockout mice [29]. Additionally, Akt and GLUT4 translocation of skeletal muscle was reduced in STZ-induced diabetic rats [8] and impaired in diabetic patients [30]. Zhou et al. [26] consistently reported that glucose uptake was not induced by phosphorylation of Akt nor the expression and translocation of GLUT4 when insulin levels were low. In the present study, administration of SE had no significant effect on GLUT 4 translocation and the phosphor-Akt/Akt ratio, suggesting that the hypoglycemic effect of SE was not related to glucose uptake by skeletal muscle.

In this study, administration of SE also significantly decreased the concentration of triglycerides as well as total- and LDL-cholesterol. Previous studies have consistently showed that SE decreases cholesterol levels by reducing hepatic cholesterol synthesis and increasing cholesterol excretion into feces [6,11]. Chung et al. [16] also observed that SE markedly decreased the serum concentration of total-cholesterol, suggesting that HMG-CoA reductase might be responsible. Therefore, these results indicate that SE may have beneficial bioactive components that could exert blood lipid profiles in humans [11], but whether SE has the ability to reduce cholesterol synthesis through HMG-CoA reductase in vivo warrants further investigation.

Our study had a few limitations. We did not measure the active components in the $80 \%$ ethanol extract of sorghum or determine whether the protein expression was due to a change in mRNA levels. We also did not observe the dose dependency of SE. In conclusion, the oral administration of SE significantly reduced blood glucose concentration by inhibition of hepatic gluconeogenesis, particularly via suppression of PEPCK and p38 expression, and increased AMPK expression in STZ-induced diabetic rats.

\section{Abbreviations}

Akt: Protein kinase B; AMPK: Adenosine monophosphate activated protein kinase; G: Glibenclamide; GLUT: Glucose transporter; p38: p38 mitogen- activated protein kinase; PEPCK: Phosphoenolpyruvate carboxykinase; SE: Sorghum extract; STZ: Streptozotocin.

\section{Competing interests}

The authors declare that they have no competing interest.

\section{Authors' contributions}

JK conducted the research and wrote the manuscript. YP designed the research and had primary responsibility for the final content. All authors read and approved the final manuscript.

\section{Acknowledgements}

This work was supported by a grant from the Korea Research Foundation funded by the Korea Rural Development Administration (PJ006983201005).

Received: 21 August 2012 Accepted: 20 November 2012 Published: 27 November 2012

\section{References}

1. Craig ME, Hattersley A, Donaghue KC: Definition, epidemiology and classification of diabetes in children and adolescents. Pediatr Diabetes 2009, 10:3-12.

2. Agius L: New hepatic targets for glycaemic control in diabetes. Best Pract Res Clin Endocrinol Metab 2007, 21:587-605.

3. Standaert ML, Ortmeyer HK, Sajan MP, Kanoh Y, Bandyopadhyay G, Hansen BC, Farese RV: Skeletal muscle insulin resistance in obesity-associated type 2 diabetes in monkeys is linked to a defect in insulin activation of protein kinase C-zeta/lambda/iota. Diabetes 2002, 51:2936-2943.

4. Cao W, Collins QF, Becker TC, Robidoux J, Lupo EG Jr, Lupo EG, Xiong Y, Daniel KW, Floering L, Collins S: p38 Mitogen-activated protein kinase plays a stimulatory role in hepatic gluconeogenesis. J Biol Chem 2005, 280:42731-42737.

5. Pilkis SJ, Granner DK: Molecular physiology of the regulation of hepatic gluconeogenesis and glycolysis. Annu Rev Physiol 1992, 54:885-909.

6. He A, Liu X, Liu L, Chang Y, Fang F: How many signals impinge on GLUT4 activation by insulin? Cell Signal 2007, 19:1-7.

7. Xia X, Yan J, Shen Y, Tang K, Yin J, Zhang Y, Yang D, Liang H, Ye J, Weng J: Berberine improves glucose metabolism in diabetic rats by inhibition of hepatic gluconeogenesis. PLoS One 2011, 6:e16556-e16565.

8. Liu SH, Chang YH, Chiang MT: Chitosan reduces gluconeogenesis and increases glucose uptake in skeletal muscle in streptozotocin-induced diabetic rats. J Agric Food Chem 2010, 58:5795-5800

9. Liu M, Wu K, Mao X, Wu Y, Ouyang J: Astragalus polysaccharide improves insulin sensitivity in KKAy mice: regulation of PKB/GLUT4 signaling in skeletal muscle. J Ethnopharmacol 2010, 127:32-37.

10. Awika JM, Rooney LW: Sorghum phytochemicals and their potential impact on human health. Phytochemistry 2004, 65:1199-1221.

11. Kim JS, Hyun TK, Kim MJ: Anti-oxidative activities of sorghum, foxtail millet and proso millet extracts. Afr J Biotechnol 2010, 9:2683-2690.

12. Sikwese FE, Duodu KG: Antioxidant effect of a crude phenolic extract from sorghum bran in sunflower oil in the presence of ferric ions. Food Chem 2007, 104:324-331.

13. van Rensburg SJ: Epidemiologic and dietary evidence for a specific nutritional predisposition to esophageal cancer. J Natl Cancer Inst 1981, 67:243-251

14. Hoi JT, Weller CL, Schlegel VL, Cuppett SL, Lee JY, Carr TP: Sorghum distillers dried grain lipid extract increases cholesterol excretion and decreases plasma and liver cholesterol concentration in hamsters. J Funct Foods 2009, 1:381-386.

15. Carr TP, Weller CL, Schlegel VL, Cuppett SL, Guderian DM Jr, Johnson KR: Grain sorghum lipid extract reduces cholesterol absorption and plasma non-HDL cholesterol concentration in hamsters. J Nutr 2005, 135:2236-2240.

16. Chung IM, Kim EH, Yeo MA, Kim SJ, Seo MC, Moon HI: Antidiabetic effects of three Korean sorghum phenolic extracts in normal and streptozotocin-induced diabetic rats. Food Res Int 2011, 44:127-132.

17. Remesar X, Fernández-López JA, Blay MT, Savall P, Salas A, Díaz-Silva M, Esteve M, Grasa MM, Alemany M: Effect of oral oleoyl-estrone on adipose tissue composition in male rats. Int J Obes Relat Metab Disord 2002, 26:1092-102. 
18. Park JH, Lee SH, Chung IM, Park Y: Sorghum extract exerts an anti-diabetic effect through improvement of insulin sensitivity via PPAR- $\gamma$ in mice with high-fat diet. Nutr Res Pract 2012, 6:322-327.

19. Kim JS, Hyun TK, Kim MJ: The inhibitory effects of ethanol extracts from sorghum, foxtail millet and proso millet on a-glucosidase and a-amylase activities. Food Chem 2011, 124:1647-1651.

20. Lakshmi KB, Vimala V: Hypoglycemic effect of selected sorghum recipes. Nutr Res 1996, 16:1651-1658.

21. Okamoto T, Kanemoto N, Ban T, Sudo T, Nagano K, Niki I: Establishment and characterization of a novel method for evaluating gluconeogenesis using hepatic cell lines, H4IIE and HepG2. Arch Biochem Biophys 2009, 491:46-52.

22. Qiao L, MacDougald OA, Shao J: CCAAT/enhancer-binding protein alpha mediates induction of hepatic phosphoenolpyruvate carboxykinase by p38 mitogen-activated protein kinase. J Biol Chem 2006, 281:24390-24397.

23. Cheong J, Coligan JE, Shuman JD: Activating transcription factor-2 regulates phosphoenolpyruvate carboxykinase transcription through a stress-inducible mitogen-activated protein kinase pathway. J Biol Chem 1998, 273:22714-22718.

24. Berasi SP, Huard C, Li D, Shih HH, Zhong W, Paulsen JE, Brown EL, Gimeno RE, Martinez RV: Inhibition of gluconeogenesis through transcriptional activation of EGR1 and DUSP4 by AMP-activated kinase. J Biol Chem 2006, 281:27167-27177.

25. Andreelli F, Foretz M, Knauf C, Cani PD, Perrin C, Iqlesias MA, Pillot B, Bado A, Tronche F, Mithieux G, Vaulont S, Burcelin R, Viollet B: Liver adenosine monophosphate-activated kinase-alpha2 catalytic subunit is a key target for the control of hepatic glucose production by adiponectin and leptin but not insulin. Endocrinology 2006, 147:2432-2441.

26. Zhou L, Yang Y, Wang X, Liu S, Shang W, Yuan G, Li F, Tang J, Chen M, Chen J: Berberine stimulates glucose transport through a mechanism distinct from insulin. Metabolism 2007, 56:405-412.

27. Dugani $C B$, Klip A: Glucose transporter 4: cycling, compartments and controversies. EMBO Rep 2005, 6:1137-1142.

28. van Dam EM, Govers R, James DE: Akt activation is required at a late stage of insulin-induced GLUT4 translocation to the plasma membrane. Mol Endocrinol 2005, 19:1067-1077.

29. Kadowaki T: Insights into insulin resistance and type 2 diabetes from knockout mouse models. J Clin Invest 2000, 106:459-465.

30. Kahn BB, Rosen AS, Bak JF, Andersen PH, Damsbo P, Lund S, Pedersen O Expression of GLUT1 and GLUT4 glucose transporters in skeletal muscle of humans with insulin-dependent diabetes mellitus: regulatory effects of metabolic factors. J Clin Endocrinol Metab 1992, 74:1101-1109.

doi:10.1186/1743-7075-9-106

Cite this article as: Kim and Park: Anti-diabetic effect of sorghum extract on hepatic gluconeogenesis of streptozotocin-induced diabetic rats. Nutrition \& Metabolism 2012 9:106.

\section{Submit your next manuscript to BioMed Central and take full advantage of:}

- Convenient online submission

- Thorough peer review

- No space constraints or color figure charges

- Immediate publication on acceptance

- Inclusion in PubMed, CAS, Scopus and Google Scholar

- Research which is freely available for redistribution 